\title{
Evaluation of Post-Harvest Practices on Turmeric (Curcuma Longa Linn) In Relation to Quality among Selected Four Barangays of MarantaoLanao Del Sur
}

\author{
Dr. SubaidaU. Bunsa \\ Mindanao State University, Marawi City, Philippines
}

\begin{abstract}
Growing turmeric is ideal since this crop has wider adaptability in terms of climate and soil condition. This crop can provide more benefits because of its medical and nutritional value. It adds palatability to dishes, and can be considered as income alternative crop during period of cash scarcity. Most housewives living in the local areas are motivated to grow turmeric because of its advantages. The demand of turmeric rhizomes is high and the crop was marked as high-valued crops. Since it is an ingredient in the preparation of the dishes by most people not only in Lanaodel Sur but throughout the country, the availability of this crop should always be within reach. Part of the turmeric that is used in the rhizome which is processed into powder form before it is used as ingredient in food preparation, and sometimes a cash earning endeavor. Turmeric powder processing can be considered as an old practice in household since it has many uses. The objective of this research was to obtain information about post-harvest practices among turmeric growers and powder processors in four selected barangays of Marantao, Lanaodel Sur. To this aim, participant were distributed a survey questionnaire made simple to provide the respondents an easy way in answering. It was found outhat turmeric growing is highly profitable because of its market potential, and it can be a source of additional income to housewives because backyard growing is feasible, even if the area is partly shaded provided that the 4 area is reach in organic matter, the growing of this crop is feasible. The culture is simple because it does not require any chemical fertilizer. In powder processing, the method is easy because simple grinder or pestle with mortar can be used.
\end{abstract}

Keywords: Agriculture, Bulb and Splits, Culture, Curcumin, Farm size, Fingers, Grinding, Milling, Meranao, Oleoresins, Organoleptic, Organoleptic Testing, Post-harvest System, Post-harvest handling, Rhizomes, Tenant Farmers, Tubers, Zygomorphic.

\section{Introduction}

One of the major spices that are used as ingredient in preparing dishes and other forms of food among Filipinos particularly the Meranaos is the luyangdilaw or kalawag which is also known locally as turmeric (Curcuma longa L.). It is observed in Meranao people that in cooking, satisfactory judgment on the palatability of their dished being prepared are not on the method it was cooked but it is on the mixture of turmeric powder. Since turmeric is considered as one of the basic needs in cooking, its availability in the kitchen is always taken into consideration. To have continued supply of this crop, most homemakers utilize the vacant space in their backyard for growing turmeric. Turmeric crop is an ancient and sacred spice of India known as "Indian saffron" and is the most important commercial spice crop grown in India. It is used in diversified forms as condiments, flavoring and coloring agent and as a principal ingredient in Indian culinary as curry powder. As of today, every individual that uses spices in preparing menu aims not only for the palatability but also for its contribution to health condition. Turmeric is one of the most crops not only because of its color and palatability but also because of its benefits since this crops has anti-cancer and anti-viral activities, hence it is used in the drug and cosmetic industry. One of the major by-products in India is the "Kum-kum", and is popular in India. It is used in the offerings in religious and ceremonial occasions. The Kum-kun is a type of starch extracted from a particular type of turmeric.

Turmeric production in the area of Lanaodel Sur province is very ideal.However, the production is limited since price for fresh turmeric is low, and farmers produce this crop is small scale only.Turmeric becomes 
a potential spice product because of its many uses not only for condiments, but its medicinal value for some illnesses. The municipality of MarantaoLanao del Sur province is noted as an area for turmeric production. This crop was grown in small scale production. Turmeric growers are fully equipped with knowledge and skills on the cultural management and practices for turmeric production. One of the components in turmeric production is the postharvest technology. The food post-production sector is a vital component of the food system of help turmeric growers reduce losses and obtain more income. On the other hand, losses are attributed to a combination of factors affecting the way the crop is grown, harvested, cleaned, handled, dried, stored, milled, and marketed. Losses are either due to deterioration of products, and or outright physical loses that leads to commercial value reduction. Significant gains have been made in understanding the socio-economic environment under which the industry operation, and in understanding the post-harvest processes and the biochemical properties of the turmeric as it relates to maintaining the quality.

\section{Conceptual Framework of the Study}

\section{INDEPENDENT VARIABLES}

\section{DEPENDENT VARIABLES}

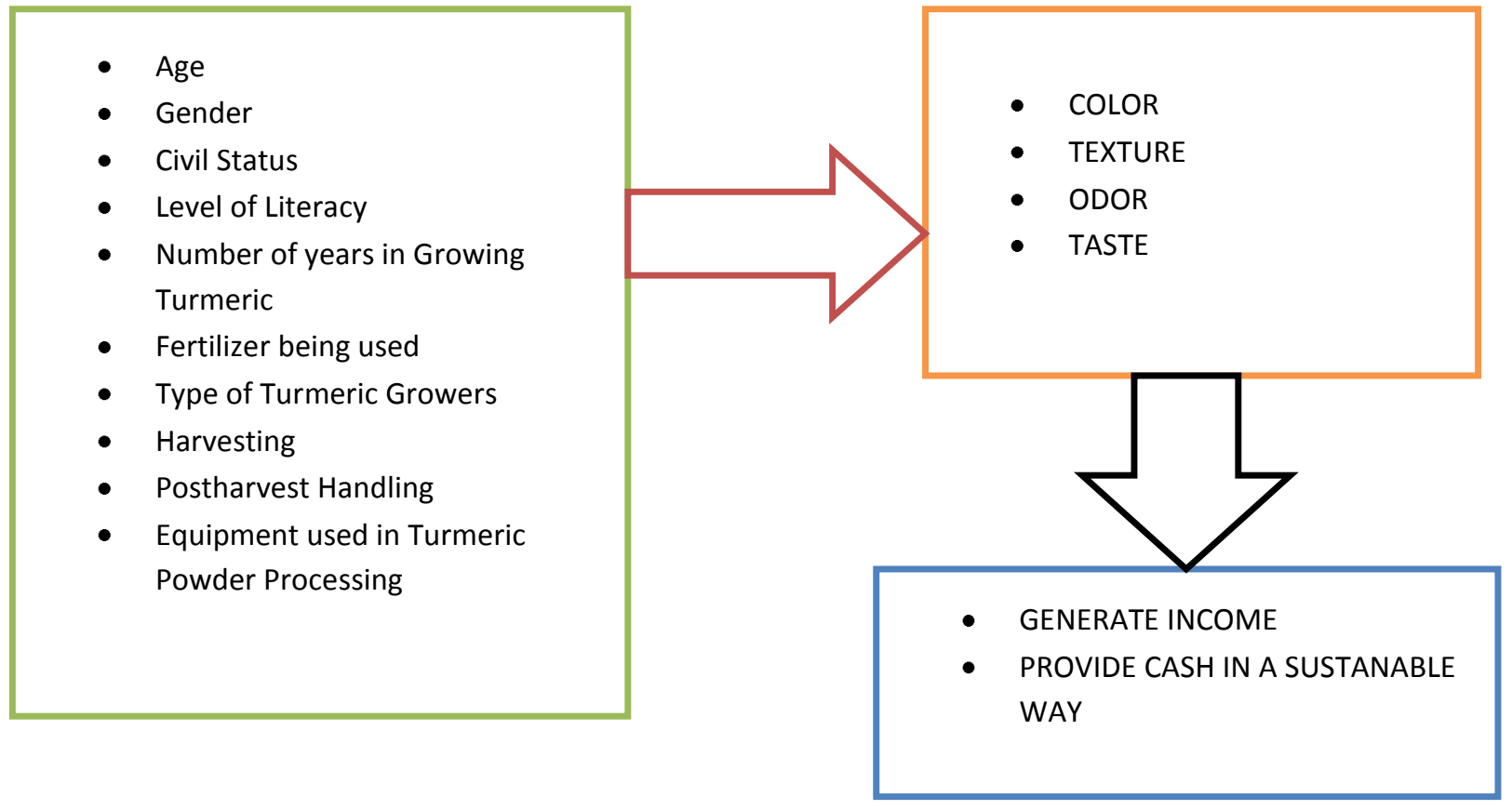

IMPACT TO RESPONDENTS

Figure 1. Conceptual Paradigm Showing the Effect of Independent Variables on the Turmeric Postharvest among Turmeric Growers in Four Selected Barangays in the Municipality of Marantao.

\section{Method}

\section{Participants}

The respondents of the study considered one hundred twenty (120) turmeric growers who were randomly selected from the barangays of the municipality of Marantao.

\section{Design}

The study uses the survey design, a procedure in quantitative research in which the researcher administer questionnaires to a small group called the sample. 


\section{Materials}

The research material used in gathering data was a survey questionnaire. The questions found in the questionnaire was simple to provide the respondents an easy way in answering the questions. It contained items that conforms the variables appearing in conceptual paradigm (Figure 1).

\section{Procedure}

There were no secondary data being gathered. Data were taken from specific respondents and in gathering data, questionnaires were distributed to the respondents. Before the researcher distributed the questionnaire, protocol was observed in which approval by the barangay Chairperson in each barangay was taken as first consideration. To avoid delay in gathering the data, the questions were translated in Meranao dialect to avoid difficulties in understanding some words found in the questionnaire. As such, the researcher used simple and understandable terminologies to ensure comprehension by the respondents.

\section{Results}

The results conformed to the statement of Dr. S. Azam Ali, (2007) that grinding can be a method of adding value to a product. Simple grinding can be used to turn rhizomes particles into a fine powder. Grinding through stones is the traditional way that usually use by the farmers. After grinding the powder is sieved through different mesh screens until a uniform, fine powder is obtained as added by Dr. S. Azam Ali (2007). As stated by Anne Plotto, et Al. (FAO, 2004), slicing the rhizomes reduces drying time and yield with lower moisture content as well as better curcuminoid extractability.

\section{Descriptive statistics}

Table 1. Distribution of Respondents by Barangay

\begin{tabular}{|l|c|c|}
\hline \multicolumn{1}{|c|}{ Barangay } & Number of Respondents & Drawn Sample Size \\
\hline Matampay & 30 & 25 \\
\hline Maul & 30 & 25 \\
\hline Kawayan & 30 & 25 \\
\hline Inudaran & 30 & 25 \\
\hline Overall total & 120 & 100 \\
\hline
\end{tabular}

Random sampling was used in the selection of participants in the study. There were four barangays in the Municipality of Marantao used as a source of data and thirty (30) turmeric growers were randomly taken as respondents.

Table 2.The frequency of female and male turmeric growers

\begin{tabular}{|c|c|}
\hline Gender & Frequency \\
\hline Female & 106 \\
\hline Male & 14 \\
\hline Total & 120 \\
\hline
\end{tabular}

This indicates that turmeric growing was done majority by female with a reason to have continues supply of turmeric powder as an ingredient in preparing dishes and most food at home are prepared by mother who knows best what is good and healthy food for the whole family (Amy Cavosora, 2010).

\section{Discussion}

Turmeric is one of the Horticultural crops that is classified as spice crop. Its name appears to derive from the Latin "terra merita" (merited earth) or turmeryte, possible related to saffron. It is known as "terremerite" in French and simpy as "yellow root" in many languages. In many cultures, its name is based on the Latin word "curcuma" (Aggarwal BB, Subdaram C, Malani N, Ichikawa H, 2007).For many centuries, the use of turmeric dates back nearly 4000 years to the Vedic culture in India, where it was used as a culinary spice 
and had some significance. Asian countries, Africa, and Jamaica traditionally used turmeric as spicies, condiment and herbal medicine since $18^{\text {th }}$ century. (Aggarwal BB, Sundaram C, Malani N, Ichikawa H, 2007).

Today, turmeric is wisely cultivated in the tropics and goes by different names in different cultures and countries. In North India, turmeric is commonly Called "Haldi" a word derived from the Sanskrit word harida, and in the sounth it is called "Manjal" a word that is frequently used in ancient Tamil literature (Aggarwal BB, Sundaram C, Malani N, Ichikawa H, 2007).In the Philippines, turmeric is locally known as luyangdilaw, kalawag or dulaw (http://www/olx.ph/index.php/view+classifieds/id/67140395/).

Turmeric (curcuma longa) is rhizomatous herbaceous perennial plant of the ginger family, Zingiberaceae. Aggarwal B. et.al. (2007), said that turmeric plant would reached up to $1 \mathrm{~m}$ tall, highly branched, yellow to orange, cylindrical, aromatic rhizomes are found. The leaves are alternative and arranged in two rows. Parts of this plant includes leaf sheath, false stem right after the leaf sheath, petiole, and leaf blade. The petiole is 50 to $115 \mathrm{~cm}$ long while leaf blades ranges from 76 to $115 \mathrm{~cm}$ long and reach rarely up to $230 \mathrm{~cm}$. They have a width of $45 \mathrm{~cm}$ and are oblong to elliptic narrowing at the tip. Light orange is the usual color of youn turmeric rhizomes, while when it matured it turns to darker orange.

According to Ali, (2007), turmeric (Curcuma domestica L.) is an erect perennial plant that is grown as an annual crop for its rhizome. It belongs to the same family as ginger (Zingiberaceae) and grows in the same hot and humid tropical climate. The rhizome is a deep bright yellow colour and similar in size form to the ginger rhizome. The plant originated in the Indian Sub-continent and today India is the world leading producer and consumer of turmeric. Turmeric is sometimes called as "Indian Saffron" as it plays an important role in India culture- it is essential ingredient of curry, used in religious festivals, as a cosmetic and herbal medicine due to its medicinal value. At present, many countries already cultivate this turmeric plant including West Indies, Australia, Africa, Peru, Sri Lanka, Bangladish, Indonesia and other Asian countries.

Fresh young rhizomes can be eaten raw as appetizer. It is also an active ingredient in the traditional Malay anti-aging product called "jamu" and herbal remedy. Turmeric impact a natural yellow color to rice, glutinous rice, meat, sauces and other dishes. So if one comes to Asia and get hold of a packet of spice powder with turmeric as an ingredient, the yellow color that stains ones fingers and utensils may not be the toxin/poison one's worry with a dishwasher as stated by Aggarwal(2007).

According to Agawam BB, Sundaram C, Malani N, Ichikawa H, (2007) turmeric is native in Southeast India, and needs temperatures between 20 and $30^{\circ} \mathrm{C}\left(68\right.$ and $\left.86^{\circ} \mathrm{F}\right)$ and a considerable amount of annual rainfall to thrive. The distribution of turmeric reaches to different areas of the world including the Philippines in and about towns, sometimes in open places and sometimes planted in small backyard areas.

Achaet.al. (2012) illustrated that the method of turmeric propagation is through asexual propagation utilizing the rhizomes as planting material. The ideal month for turmeric planting is during September or October, when the soil is in warm condition. The rhizomes should be planted 5-7 deep along the ridges, usually about 30-45 cm apart and with 15-30 between plants. This crop is best planted by setts approximately $1,700 \mathrm{~kg}$ of sett are required to be hectare. Like other herbaceous plants turmeric need to be broken up and fresh pieces will be planted every 3 to 4 years interval. Turmeric will grow effectively in a soil with enriched organic minerals with a maximum exposure to sunlight. Water supply should be regular enough not to cause roots to decay. Extra nutrition can be added to the soil by using different kinds of fertilizers as stated by Jagadeeswaran R. et al (2005) \&Dohroo, (2007).

Turmeric plant is ready to harvest based on its appearances as indicated by the drying of the plant and stem, approximately 7 to 10 months after planting, depending on cultivar, soil and growing conditions. The rhizome bunches are carefully dug out manually with spade, or the soil is first loosen with a small digger, and clumps manually lifted. Cutting leaves before lifting the rhizomes is better method of harvesting. The process of harvesting and storing varies from farmers to farmers, but generally theRhizomes are cleared from adhering soil by soaking in water, and long roots are removed as well as leaf scales and then cured and processed to be stored for the next cropping. Rhizomes for seed purposes must be stored in well-ventilated rooms to minimize rot, but covered with the plant dry leaves to prevent dehydration (Anne Plotto, et. al. FAO, 2004, pages 4). The rhizomes are ready for harvesting in about 7 to 9 months after planting and the expected yield would be 13 to 35 t/ha of fresh turmeric stated by Achaet.al., (2012). 
Michaels (2014) stated that the rhizomes of turmeric can be harvesting 9 to 10 months after planting, and there are indications of maturity that can be observed, such as the appearance of the lower leaves turned yellow, stems dried up. Cutting the leaves before lifting the rhizomes is more ideal practiced. The rhizome bunches are carefully dug out manually with a spades, or the soil is first loosen with a small digger, and clumps is manually lifted. Leaf scales of the harvested rhizomes should be removed and soak in water for washing before further processing to its intended purpose of uses or stored for the next year's planting. He added that rhizomes for seed purposes must be stored in well-ventilated rooms to minimize rot, but covered with dried leaves of plant to prevent dehydration. On the other hand, Ali (2007) said that turmeric is harvested when the plants are between 7 and 10 months of age, when the stems and leaves start to dry out and die back. In harvesting the rhizome is uprooted from the ground carefully to avoid cutting or bruise. After harvesting, sweating will be done by removing the leaves, leaf scale, and roots from the plant and then washed to remove soil.

Ali, (2007), suggested that rhizomes are sliced before drying to reduce the drying time and improve the quality of the final product. The rhizomes are traditionally sliced by hand which will take for about 10 to 15 days depending on the climatic conditions, and the rhizome pieces are laid on clean concrete floors and dried in the sun. It is important that the rhizome pieces are not placed in direct sunlight as this will cause the color to fade. There are several different types of mechanical drier that are suitable for drying turmeric. The optimum drying temperature is $60^{\circ} \mathrm{C}$ - temperatures higher than this result in a darker colored product. After drying, the rhizomes are polished to removes the rough surface by hand or rhizome shaking using gunny bag of stones. In some places the rhizomes are sprinkled with a solution of ground turmeric in water during the final polishing to give the rhizomes a good color.As stated by Plotto, et. al. (FAO, 2004), slicing the rhizomes reduces drying time and yield with lower moisture content as well as better curcuminoid extractability. In rural Bolivia, slicing the boiled rhizomes is done by woman. The "FundacionPoscosecha", with the support of FAO has developed a slicing machine in order to ease the woman's work.

Setzer, (2014) Stated that women are important actors in root crops and processing. A detailed household studies to identify an alternate livelihood is more feasible and acceptable by the populace. Farmers and rural folks will have an added income for their household as climate change reduce or destroys farm produce. Women will gain extra income for their household budget. In india, the majority involved in postharvest handling are women.

According to Ali, (2007), grinding can be a method of adding value to a product. Grinding is very simple process that involves cutting and crushing into small particles, then sifting it through a series of screens of different mesh size, to get a fine powder.In the food industry, the turmeric powder is mostly used to color and flavor particularly inmustard and curry. It is also used in chicken bouillon and soups, sauces, gives, and dry seasoning. Recently the powder has been used as a colorant in cereals (http://www.turmeric.8m.com/standards.html).

Hadhazy (Jan.6, 2012), stated that one of the criteria in the assessment of the turmeric powder is the quality. The basis in describing the quality of turmeric powder is based on the character like the color and odor. The odor is the critical element in assessing the product. The property of turmeric powder can be distinguished in terms of odor and this is the only method in describing the product. He added that the basic description used is sweet, pungent, acrid, fragrant, warm, dry or sour. The most common characteristics of turmeric powder are the color, tecture and odor and these are the parameters in evaluating the quality of the products. The evaluation of the product characters is called organoleptic testing and this can be done using the sensory organ (Abe Y, Hahimoto S, Horie T., 1999).

This study was conducted to obtain information about postharvest practices among turmeric growers and powder processors in four selected barangays of Marantao, Lanaodel Sur. The data show that (28\%) belongs to age 40 years old and below, followed by age 41-55 years old with a percentage of (36\%); and age from 56 years old and above had a percentage of (36\%) as well. The age percentage majority of the turmeric growers were female. It was observed that the highest percentage of turmeric growers were married respondents in which the percentage is $(62 \%)$, followed by widow having $(33 \%)$, and the lowest was found in single with $(4 \%)$ and separated is $(1 \%)$. 
The data show that mostly married woman did the turmeric growing in order to have continuous supply of turmeric powder as ingredient in preparing dishes. Moreover, most food at home is prepared by mothers as they know best what good and healthy food for the whole family is.

Correlation analysis results show that there is significant relationship between the age of the respondents and their level of literacy in the production of turmeric $\left(x^{2}=13.439, p\right.$-value $\left.<0.05\right)$. It means the null hypothesis is rejected. There was also a significant relationship between the age of the respondents and the number of years in the production of turmeric $\left(x^{2}=8.971\right.$, p-value $\left.<0.05\right)$. It also means the null hypothesis is rejected. However, there was no significant relationship between the age of the respondents and the use of fertilizer in the production of turmeric $\left(\mathrm{x}^{2}=6.262\right.$, $\mathrm{p}$-value $\left.<0.05\right)$. It means the null hypothesis is accepted.

\section{Conclusion}

Turmeric growing is highly profitable because of its market potential, and it can be a source of additional income for homemakers because backyard growing is feasible. Even if the area is partly shaded, provided that the area is rich in organic matter, the growing of this crop is feasible. The culture is simple because it does not require any chemical fertilizer. In powder processing, the method is easy because simple grinding or pestle with mortar can be used.

\section{References}

[1] Abe Y, Hashimoto S, Horie T. (1999). curcumin inhibition of inflammatory cytokine production by human peripheral blood monocytes and alveolar macrophages. Pharmacol Res.

[2] Abellanosa, Allan and Pava, Herminio M. (1987).Introduction to Crop Science. Publication Office, Central Mindanao University, Musuan, Bukidnon, Philippines.

[3] Agarwal, Bharat B. (2011). Turmeric, the Golden Spice http://www.itdg.org/html/technical_enquiries/docs/solar_drying.pdf

[4] Aggarwal BB, Sundaram C, Malani N, Ichikawa H. (2007). “Curcumin: The Indian solid gold”. AdvExp Med Biol595 (1): 1-75.

[5] Bautista, O.k., (2007). $2^{\text {nd }}$ edition.Postharvest Technology for Southeast Asian Perishable Crops. University of the Philippines, Los Baños, Laguna.Pp.89, 90.

[6] Cavosora, Amy. (2010). Yellow magic of turmeric.Philippine Daily Inquirer.

[7] Plotto, Anne, et.al. 22/04/2004. TURMERIC: Post-Production Management. Food and Agriculture Organization of the United Nation (FAO) AGST.

[8] Michaels, Frances, (2014). TURMERIC GROWING INFORMATION http://pubs.acs.org/journal/jacsat, viewed June, 2014 